\title{
OPEN The size and shape of parasitic larvae of naiads (Unionidae) are not dependent on female size
}

\author{
Adam M. Ćmiel ${ }^{1}$, Jacek Dołęga ${ }^{1 凶}$, David C. Aldridge ${ }^{2}$, Anna Lipińska ${ }^{1}$, Feng Tang ${ }^{2}$, \\ Katarzyna Zając ${ }^{1}$, Manuel Lopes-Lima ${ }^{3}$ \& Tadeusz Zając ${ }^{1}$
}

The naiads, large freshwater mussels (Unionida), have very long life spans, are large-bodied, and produce thousands to millions of larvae (glochidia) which typically must attach to host fish tissues to metamorphose into a juvenile mussel. Glochidia develop within a female's marsupial gill demibranch, thus their number is restricted by female size. However, larger mussels acquire more energy, which could be invested in either larger-sized glochidia, in a more glochidia, or a combination of both. The high level of host specialization seen in many naiads may constrain glochidial size and shape around a narrow optimum, while naiads that use a wide range of host fishes may be predicted to possess greater plasticity in glochidial morphology. In this paper, we investigated the relationship between maternal body size and progeny body size and shape, aided by modern digital microscopy. We analyzed the between- and within- species variation of glochidia size and shape relative to female size in four widespread species of European naiads: Anodonta anatina, Anodonta cygnea, Unio crassus and Unio tumidus. Whereas the total reproductive output is collinear with female body size, substantial differences between species in glochidia size were found within genus Anodonta, but not genus Unio where glochidial size is remarkably consistent. The glochidial shape, however, differed within both Unio and Anodonta. We interpret this constant within-species glochidial size in Unio as reflecting a constraint imposed by the likelihood of successful transmission onto and off from a narrow range of hosts, whereas their shape seems to be less constrained. The Anodonta species, inhabiting a wide spectrum of habitats and using more than twice the number of fish hosts than Unio spp., have larger glochidia with greater variation in size and shape. Our results suggest that measures of glochidial variability may also serve as an indicator of host specificity in other naiads.

Parental investment into offspring is often set against a framework of $\mathrm{r}$ - and $\mathrm{K}$-strategies ${ }^{1}$, forming a continuum, bounded by two end-point strategies: an r-strategist would be characterised by the production of many small offspring, which mature early, have a short life expectancy, and a high mortality rate, whilst a K-strategist would invest in few large offspring, with a slow maturation rate, a relatively high survival rate and are long-lived. However, in most systems the observed variation in life-history strategies is too complex to be explained by an $\mathrm{r}-\mathrm{K}$ continuum alone ${ }^{2}$. This complexity is exemplified in the naiads, large freshwater mussels (Unionida), which are among the most threatened animal groups on the planet ${ }^{3,4}$ and whose biology remains poorly studied ${ }^{5}$. Intriguingly, the life history and reproductive strategy of naiads reflect a combination of traits from both $r$ - and K-strategies: they produce many offspring of microscopic size with low investment in each individual, yet adults are relatively large (e.g. Ref. ${ }^{6}$ ), with some species only reaching maturity over 30 years ${ }^{7}$, and a life expectancy of more than 100 years ${ }^{6,8}$ with individuals reproducing many times through their lifetime.

The enormous fecundity of naiads (ranging from thousands to millions of eggs per female ${ }^{9}$ ) is strongly related to body size ${ }^{10-12}$, both within and among species, and fecundity typically increases with female shell length ${ }^{13}$. However, life-history traits in Unionidae are highly variable within and among species, and very little is known about energy allocation in reproduction and related trade-offs (e.g. number vs size of the offspring in relation to parent growth vs reproduction). Indeed, some research suggests that developing glochidia are supplied by the female with calcium carbonate for shell production ${ }^{14-17}$, which may indicate an additional investment of females into their offspring. This group provides a particularly interesting opportunity for the analysis of life-history

${ }^{1}$ Institute of Nature Conservation, Polish Academy of Sciences, al. A. Mickiewicza 33, 31-120 Kraków, Poland. 'Department of Zoology, The David Attenborough Building, University of Cambridge, Pembroke Street, Cambridge CB2 30Z, UK. ${ }^{3} \mathrm{CIBIO} / \mathrm{InBIO}$-Research Center in Biodiversity and Genetic Resources, University of Porto, Campus Agrário de Vairão, 4485-661 Vairão, Portugal. ${ }^{\circledR}$ email: dolega@iop.krakow.pl 
trade-offs: naiads differ from most other organisms in their possession of an obligatory parasitic stage of their larvae, which is necessary to complete their ontogenic development ${ }^{18}$. To complete the life cycle the larva (glochidium), after being expelled by the female into the water column, must typically attach to the gills or fins of a host fish ${ }^{19-21}$. However, fewer than one in 1 million find a suitable host and survive ${ }^{22-24}$, suggesting that selection will act strongly towards optimised infestation efficiency and driving a very narrow variation around optimal glochidial phenotypes. The degree of host specificity varies among species of naiads from specialists able to successfully parasitize only one or a few closely related fish species to generalists which can complete development on a taxonomically wide range of fish species ${ }^{25}$. Host specialism/generalism is likely to further drive trade-offs in glochidial investment, with selection potentially favouring narrower phenotypic variability in the glochidia of specialists than in generalists.

The probability of fish infestation will determine population-level recruitment dynamics ${ }^{26}$, and the infestation probability should depend on frequencies of the encounter between larva and fish host which in turn should depend on the local density of both glochidia and fish. The glochidium is equipped with a larval thread (Ref. ${ }^{7}$ and citations therein) which is assumed to enable it to float in the water or attach to roots and aquatic vegetation, or the gills or fins of its fish host. The low investment in individual glochidia is reflected by their low flesh content $^{27}$, simple morphology ${ }^{9}$, and microscopic size (from 0.05 to $0.45 \mathrm{~mm}^{12}$ ).

The brooding capacity of a female, and thus the maximum number of glochidia in a brood, should be directly related to the volume of marsupia, which in turn is somewhat constrained by shell volume. Because infestation probability is determined by the encounter rate with fish, species that broadcast free glochidia typically possess extraordinarily high fecundity at the cost of reduced glochidial size to maximize the probability of host infection ${ }^{7}$. This generates selection on the optimal size of glochidia, balancing efficiency of successful infestation upon fish against maximal propagule number. On the other hand, there is some evidence of glochidia size being larger than expected in nutrient-rich environments ${ }^{28}$, which may enable them to live longer, thus increasing the likelihood of fish infestation; suggesting that additional resources may mediate the trade-offs between propagule number and size.

A further component of glochidium morphology that will be subject to selection is their shape, which is expected to influence infestation probability ${ }^{29}$. Glochidium shape and morphology have been shown to vary depending on the location of likely attachment upon on the host fish. For example, glochidia of species that target host gills are typically small and rounded, whilst those that encapsulate scales and fins typically possess large hooks ${ }^{19}$.

In this paper, we investigated the relationships between shell length of the female, glochidia size (length), glochidia shape and glochidia number in four species of European Naiads; two of the genus Anodonta (Anodonta anatina, Anodonta cygnea) and two of the genus Unio (Unio crassus and Unio tumidus). We aimed to fill the gap in knowledge about this important life-history stage of naiads by answering three key questions: (i) Do large freshwater mussel females invest more in individual progeny size than do small females? (ii) Is glochidium size and shape plastic or highly constrained between populations of the same mussel species? (iii) Do mussel species with a wider range of host fishes (i.e. Anodonta spp.) show greater variability in glochidia size and shape than those species that use a narrow host range (i.e. Unio spp.)?

\section{Materials and methods}

Mussel collection, glochidia and marsupia measurements. Wild mussels used in the study were collected using bottom-scrapers (rake with netting) in lakes and by wading with bathyscopes in rivers. Presence of glochidia was identified in each captured mussel by the gentle opening of the shell valves and visual inspection of the marsupia. Maturity of glochidia used in analyses was confirmed by evaluation of their morphology ${ }^{30}$ and exposing a subsample (approx. 30 ind.) to a salt $(\mathrm{NaCl})$ solution; closure of valves indicated glochidia were mature and alive ${ }^{31}$, after which the glochidia were preserved in 95\% ethanol. Only gravid females with full marsupia and fully developed glochidia were used for collecting samples. Four species of naiads were used: 33 females of Anodonta cygnea were collected on 26th and 31st March 2015 from Zalew Pińczowski reservoir near the town of Pińczów (central Poland; 50 31' 03.57" N, 20 31' 03.57" E); 37 individuals of Anodonta anatina were collected on 22nd January 2020 from Zesławice No. 2 reservoir near Kraków (southern Poland; $50^{\circ} 06^{\prime}$ $30.9^{\prime \prime} \mathrm{N}, 20^{\circ} 01^{\prime} 51.2^{\prime \prime} \mathrm{E}$ ); 24 individuals of Unio tumidus were collected on 8th May 2019 from the river Belnianka near Marzysz (central Poland; 50 46 41.09" N, 20 42' 28.97" E); and 15 individuals of Unio crassus were collected on the 2nd and 19th June 2018 from the river San near Procisne (south-east of Poland; 49 $11^{\prime} 50.86^{\prime \prime} \mathrm{N}$, $22^{\circ} 40^{\prime} 56.89^{\prime \prime} \mathrm{E}$ ). To enable within-species comparisons between different populations, gravid U. crassus females were collected from two additional populations: 11 individuals at vicinity of Lubaszowa in June 2018 from the river Biała (south of Poland; $49^{\circ} 51^{\prime} 37^{\prime \prime} \mathrm{N}, 21^{\circ} 01^{\prime} 59^{\prime \prime} \mathrm{E}$ ), and five individuals at Leńcze from the river Cedron (south of Poland; $49^{\circ} 53^{\prime} 17^{\prime \prime} \mathrm{N}, 1^{\circ} 44^{\prime} 04^{\prime \prime}$ E). For U. crassus the rivers differed in habitat characteristics: while the river San is a typical mountainous river with a rocky bottom, the river Biała is a typical river of foothills, with a pool-riffle system dominated by gravel. The river Cedron is a lowland meandering river dominated by fine sediments and with fine gravel present only in riffles. The Zalew Pińczowski reservoir and the Zasławice reservoir are seminatural, eutrophic, shallow water bodies similar to each other in general ecological characteristics. The river Belnianka is a small lowland meandering river with a sandy bottom.

Glochidia of each species were extracted from marsupia by gently shaking the marsupium content in water in a Petri dish. Released glochidia were measured under a Keyece VHX-950F microscope equipped with the software 'Find objects' and 'Measurement' functions, which allowed precise measurement of each glochidium. Only flat-positioned glochidia with completely visible valves were selected for measurement (Fig. 1a). Because in previously published papers on glochidia size the definition of 'length' and 'width' of the shell is interchanged, for this study we define the glochidium valve length accordingly to the measurements of adults, i.e. the valve 

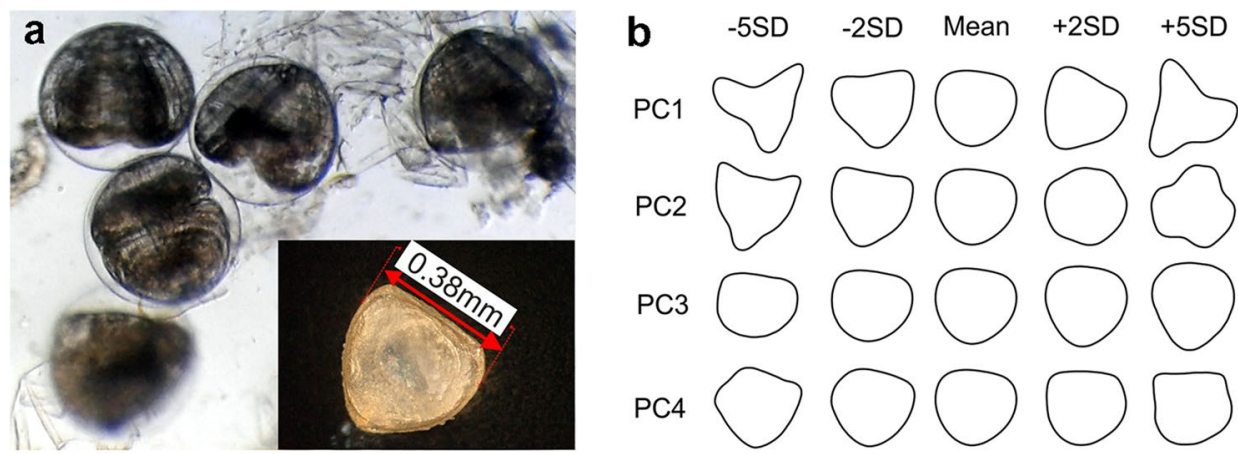

Figure 1. (a) Measurement of the length of flat-positioned glochidia of A. anatina; in the background almost fully grown glochidia of $U$. crassus still enclosed within the egg membranes. (b) Reconstructed closed contour of glochidia (mean, mean $\pm 2 \mathrm{SD}$ and mean $\pm 5 \mathrm{SD}$ ) visualizing the shape aspect described by the significant Principal Components obtained from Elliptical Fourier Descriptors.

length is defined as the longest axis of the valve (the largest distance) measured along the line parallel to shell hinge (Fig. 1a). A sample of 30 randomly selected glochidia was measured for each gravid female.

To obtain a wet mass of marsupia, gravid females with full marsupia were collected for the purpose of the other studies (A. cygnea in 2003, U. crassus in Cedron in 2011, all other samples in 2018). They were taken from the water and transported to the laboratory, where they were sacrificed and immediately dissected: full marsupia were cut off the body using surgical scissors and weighed using an electronic laboratory scale (RADWAG WLY $0.6 / 1.2 / \mathrm{D} 2$; precision $0.1 \mathrm{~g}$ ).

The effect of the preservation of glochidia in 95\% ethanol was tested on glochidia taken from the gravid $A$. anatina. This species produces the largest glochidia among analyzed species, maximising the potential for detecting any influence of alcohol preservation on glochidia size. Fifteen fresh glochidia were taken from marsupia of living mussels and immediately measured. Then, each glochidium was stored in a separate numbered plastic Eppendorf tube filled with 95\% ethanol and measured again after $72 \mathrm{~h}$.

This research was conducted in full compliance with the ethical codes and legislation of the Republic of Poland. Collection, extraction of glochidia from marsupia, and killing of protected mussel species (A. cygnea and $U$. crassus) individuals were performed under the necessary permits: DZP-WG.6401.01.26.2018.bp (U. crassus in River San), DZP-WG.6401.01.31.2018.bp (U. crassus in River Biała), DOP-OZGIZ.6401.01.106.2011. ls (U. crassus in River Cedron), WPN.I.6401.56.2015.AC and DOPweg-4201-01-12/03/jr (A. cygnea in Zalew Pińczowski reservoir).

Statistical analysis. All statistical analyses were performed using Statistica 13.1 software (Dell Inc.).

Glochidia size analyses. Because the homogeneity of variance assumption was not fulfilled, the differences in mean glochidia size between species were analysed using nonparametric Kruskal-Wallis and multiple comparisons post-hoc tests. The relationship between the wet weight of marsupium and female shell length was analyzed using Pearson $r$ correlations. The relationship between female shell length and mean length of glochidia was analyzed by fitting a linear function $g=s \times l+c$, where $g$ is a mean glochidium length, $s$ is a slope coefficient, $l$ is female shell length and $c$ is a constant.

To test the influence of female body size with the controlled influence of species, variability within given female, and interactions between the analysed factors, Mixed-design General Linear Models were constructed. The mixed design is used when there is at least one within-subjects factor and at least one between-subjects factor in the same dataset. The constructed Mixed-design GLM scheme was: length of each measured glochidium (30 continuous dependent variables), species (between-subject categorical factor), female length (between-subject continuous predictor), within subject effect (WSE, which represents the variability of glochidia length within females), and the interactions between them (species $\times$ female length, WSE $\times$ species, WSE $\times$ species $\times$ female length). From this, we analysed the influence of the variability in glochidia length within each analyzed female itself (WSE). Mixed-design GLMs were also used to analyse if variability in glochidia length within each female depends on female length (WSE $\times$ female length), depends on mussel species (WSE $\times$ species) or depends both on female length and mussel species (WSE $\times$ female length $\times$ species), which is the main advantage of this approach over analysing separately the relationship between female length and lengths of its glochidia, and analyzing differences in glochidia length between species.

In the first Mixed design GLM model, the data for U. crassus were pooled across the three rivers. To analyze if the influence of female length on glochidia size in U.crassus differed between habitats (rivers), the same Mixed design GLM model was constructed but categorical factor "species" replaced by categorical factor: "river".

To determine the significance of glochidium size between species that might be used for species determination, we applied discriminant function analysis, using measured glochidium length data. 
Glochidia shape analysis. Shape of glochidia was analyzed using Elliptical Fourier descriptors (EFDs) with SHAPE 1.3 software $^{32}$. After noise reduction, the closed contours of glochidia were chain-coded ${ }^{33}$. The EFD coefficients were calculated by discrete Fourier transformation of the chain-coded contours following the procedures given by Kuhl and Giardina ${ }^{34}$. EFDs were normalized with a procedure based on the first harmonic ellipse that corresponds to the first Fourier approximation to the contour information. Glochidia shape was approximated by the first twenty harmonics, which leads to a large number of normalized EFD coefficients. Thus, to summarize the information contained in them, we performed Principal Component Analyses (PCA) based on variance-covariance matrices. The homogeneity of variance of each principal component score between mussel species was tested with Levene's tests and because the homogeneity of variance assumption was not fulfilled, the differences in PC scores between species were analysed using nonparametric Kruskal-Wallis and multiple comparisons post-hoc tests. The effect that principal components described for shell shape was visualized in relation to the mean effect by inverse recalculation of EFDs using an eigenvector matrix. Only significant PCs were visualised, with extreme morphologies visualised for mean \pm 2 SD and mean \pm 5 SD). This enabled visualization of the shape aspect described by the given PC.

\section{Results}

In total, 3780 glochidia from 126 females were measured. Sizes of female mussels were [all measurements are expressed in $\mathrm{mm}]$ : A. anatina $(\mathrm{N}=37$, mean length $=120, \mathrm{SD}=13$, range $73-140) ;$ A. cygnea $(\mathrm{N}=33$, mean $=113$, $\mathrm{SD}=18$, range 84-146); $U$. tumidus $(\mathrm{N}=24$, mean $=91, \mathrm{SD}=16$, range 51-116); $U$. crassus from the river Biała $(\mathrm{N}=11$, mean $=64, \mathrm{SD}=5$, range 54-69); $U$. crassus from the river Cedron $(\mathrm{N}=5$, mean $=58, \mathrm{SD}=3$, range 56-63); $U$. crassus from the river $\operatorname{San}(\mathrm{N}=15$, mean $=47, \mathrm{SD}=9$, range 36-62). Measurement of the length of flat-positioned glochidium was presented at Fig. 1a.

Descriptive statistics for measured glochidia with comparison to the data from other studies are presented in Table 1 . The glochidia size varied significantly between species (Fig. 2a,b). Mean glochidium length was significantly different between species (Kruskal-Wallis test; $\mathrm{H}=113.3 ; \mathrm{df}=3 ; \mathrm{p}<0.0001$ ). Post-hoc tests (multiple comparisons) showed that the differences were significant between every pair of analysed species, except for $U$. crassus and U. tumidus (Fig. 2b).

Preservation of glochidia in ethanol had no effect on glochidia size (mean length of fresh glochidia $0.372 \mathrm{~mm}$; mean length of alcohol preserved glochidia $0.373 \mathrm{~mm}$; paired $\mathrm{t}=-1.1, \mathrm{df}=13, \mathrm{p}=0.3087$ ).

The marsupium wet weight for all studied species was highly and significantly correlated with female shell length (Pearson correlations; A. anatina: $\mathrm{r}=0.80, \mathrm{~N}=21 ;$ A. cygnea: $\mathrm{r}=0.84, \mathrm{~N}=58 ;$ U. tumidus: $\mathrm{r}=0.91, \mathrm{~N}=38$; $U$. crassus: $\mathrm{r}=0.79, \mathrm{~N}=35$; all correlations are significant at $\mathrm{p}<0.0001)$.

Fitting linear functions describing the relationship between female shell length and mean length of its glochidia for each species separately showed that the slope of regression line was not significantly different from zero in all analyzed species (A. anatina: $\mathrm{R}^{2}=0.26$, slope $=-0.0002, \mathrm{t}=-1.6, \mathrm{p}=0.123 ;$ A.cygnea: $\mathrm{R}^{2}=0.22$, slope $=-0.00009, \mathrm{t}=-1.3, \mathrm{p}=0.220 ;$. crassus: $\mathrm{R}^{2}=0.34$, slope $=0.0002, \mathrm{t}=2.0, \mathrm{p}=0.550 ;$. tumidus: $\mathrm{R}^{2}=0.35$, slope $=-0.00005, \mathrm{t}=-1.8, \mathrm{p}=0.089$; Fig. 2a).

The models controlling for other factors (Mixed design GLMs) showed that the only significant factor influencing the size of glochidia was species. All other predictors, including variability of glochidium length within a particular female (WSE), and all interaction terms were not significant (Table 2; Fig. 2a).

There was no significant difference in the glochidia length of $U$. crassus between the three populations inhabiting different rivers (Table 2).

Discriminant Function Analysis showed that glochidium length had a high discriminant power (Wilk's $\lambda=0.009 ; \mathrm{F}=4541.9 ; \mathrm{df}=3 ; \mathrm{p}<0.0001)$ and may be used in species classification. Obtained classification functions were: $a=5814.9, c=-1196.0$ in A. anatina; $a=4647.4, c=-764.5$ in A. cygnea; $a=2877.6, c=-294.0$ in $U$. crassus; $a=2968.2$, and $c=-313.0$ in $U$. tumidus, where $a$ is a regression coefficient and $c$ is a constant. The classification matrix showed that overall $93.6 \%$ of cases were classified correctly (100\% of A. anatina cases, $100 \%$ of $A$. cygnea cases, $80.6 \%$ of $U$. crassus cases and $91.7 \%$ of $U$. tumidus cases).

Glochidia shape analyses. The analysis of glochidia shape showed that the first four PCs obtained from Elliptical Fourier Descriptors explained 90.8\% of the variation in glochidia shape (PC1: 57.2\%; PC2: 22.3\%; PC3: 7.9\%; PC4: 3.4\%) and thus were selected for further analyses. The shape aspect described by each PC was presented at Fig. $1 \mathrm{~b}$.

The differences in PC scores between species were significant for all PCs: PC1 (the symmetry vs vertical axis; Kruskal-Wallis test: $\mathrm{H}=35.0 ; \mathrm{df}=3 ; \mathrm{p}<0.0001$ ), PC2 (triangular vs hexagonal shape; Kruskal-Wallis test: $\mathrm{H}=16.31 ; \mathrm{df}=3 ; \mathrm{p}=0.001$ ), $\mathrm{PC} 3$ (horizontal rectangle vs vertically extended rectangle shape; Kruskal-Wallis test: $\mathrm{H}=40.2 ; \mathrm{df}=3 ; \mathrm{p}<0.0001$ ) and PC4 (rhombic shape vs more squared shape; Kruskal-Wallis test: $\mathrm{H}=33.4$; $\mathrm{df}=3 ; \mathrm{p}<0.0001$ ). The Multiple comparisons post-hoc tests showed that in both PC1 and PC3 Anodonta species significantly differed from Unio species, while the A. anatina did not differ significantly from A. cygnea and $U$. crassus did not differ significantly from U. tumidus (Fig. 3). In PC2. U. crassus differed significantly from other species and A. cygnea differed significantly from U. tumidus (Fig. 3). In PC4 A.anatina differed significantly form A. cygnea and U. tumidus, A. cygnea differed significantly from U. crasus, while U. crassus did not differ significantly from U. tumidus (Fig. 3).

The relationship between female length and shape of its glochidia was not significant in any of the analysed mussel species: A. anatina (linear regressions; PC1: $b=0.21, p=0.445 ; P C 2: b=-0.11, p=0.701 ; P C 3: b=-0.29$, $\mathrm{p}=0.288 ; \mathrm{PC} 4: \mathrm{b}=-0.23, \mathrm{p}=0.415) ;$ A. cygnea (linear regressions; $\mathrm{PC} 1: \mathrm{b}=-0.38, \mathrm{p}=0.158 ; \mathrm{PC} 2: \mathrm{b}=0.06$, $\mathrm{p}=0.835 ;$ PC3: $\mathrm{b}=0.29, \mathrm{p}=0.302 ; \mathrm{PC} 4: \mathrm{b}=-0.07, \mathrm{p}=0.793$ ); U. crassus (linear regressions; $\mathrm{PC} 1: \mathrm{b}=-0.32$, 


\begin{tabular}{|c|c|c|c|c|c|c|c|c|c|}
\hline Species & Site & $\mathbf{N}$ & Mean $[\mathbf{m m}]$ & SD & $\operatorname{Min}[\mathrm{mm}]$ & $\operatorname{Max}[\mathbf{m m}]$ & $\begin{array}{l}\text { Range min.- } \\
\max [\mathrm{mm}]\end{array}$ & $\begin{array}{l}\text { Range/mean } \\
\text { size }\end{array}$ & Source \\
\hline \multirow{15}{*}{$\begin{array}{l}\text { Anodonta } \\
\text { anatina }\end{array}$} & & 30 & 0.36 & - & - & - & - & - & 35 \\
\hline & & - & - & - & 0.35 & 0.36 & 0.01 & - & 36 \\
\hline & & - & 0.36 & - & - & - & - & - & 37 \\
\hline & & - & 0.35 & - & - & - & - & - & 38 \\
\hline & & - & 0.36 & - & - & - & - & - & 39 \\
\hline & & - & 0.50 & 0.08 & 0.45 & 0.57 & 0.12 & 0.24 & 28 \\
\hline & & - & 0.34 & 0.02 & 0.34 & 0.42 & 0.08 & 0.24 & 28 \\
\hline & & - & - & - & \begin{tabular}{|l|}
0.27 \\
\end{tabular} & 0.57 & 0.3 & - & 40,41 \\
\hline & & - & - & - & 0.33 & 0.38 & 0.05 & - & 42 \\
\hline & & 30 & 0.36 & 0.02 & - & - & - & - & 43 \\
\hline & & - & 0.35 & - & - & - & - & - & 44 \\
\hline & & - & 0.34 & - & - & - & - & - & 45 \\
\hline & & 7 & 0.36 & 0.04 & 0.35 & 0.36 & 0.01 & 0.03 & 46 \\
\hline & & 1110 & 0.41 & 0.02 & 0.31 & 0.47 & 0.16 & 0.39 & This study \\
\hline & Mean & $\Sigma=1177$ & \begin{tabular}{|l|l|}
0.37 \\
\end{tabular} & 0.04 & 0.36 & 0.46 & 0.1 & 0.27 & \\
\hline \multirow{10}{*}{$\begin{array}{l}\text { Anodonta } \\
\text { cygnea }\end{array}$} & & 30 & 0.32 & - & - & - & - & - & 35 \\
\hline & & - & 0.35 & - & - & - & - & - & 47 \\
\hline & & - & - & - & 0.27 & 0.36 & 0.09 & - & 40,41 \\
\hline & & 2 & 0.32 & 0.05 & 0.31 & 0.34 & 0.03 & 0.09 & 48 \\
\hline & & - & 0.32 & - & - & - & - & - & 44 \\
\hline & & - & 0.31 & - & - & - & - & - & 45 \\
\hline & & - & 0.34 & - & - & - & - & - & 49 \\
\hline & & 9 & 0.35 & 0.04 & 0.34 & 0.36 & 0.02 & 0.06 & 50 \\
\hline & & 990 & 0.33 & 0.01 & 0.25 & 0.37 & 0.12 & 0.36 & This study \\
\hline & Mean & $\Sigma=1031$ & 0.33 & 0.03 & 0.31 & 0.38 & 0.07 & 0.21 & \\
\hline \multirow{7}{*}{ Unio crassus } & & - & - & - & 0.18 & 0.23 & 0.05 & - & 40,41 \\
\hline & & & 0.22 & & & & - & - & 45 \\
\hline & PL: Biała & 330 & 0.20 & 0.004 & 0.19 & 0.22 & 0.03 & 0.15 & This study \\
\hline & PL: San & 450 & 0.20 & 0.010 & 0.17 & 0.23 & 0.06 & 0.30 & This study \\
\hline & PL: Cedron & 150 & 0.21 & 0.005 & 0.20 & 0.23 & 0.03 & 0.14 & This study \\
\hline & PL: pulled & 930 & 0.20 & 0.008 & 0.17 & 0.23 & 0.06 & 0.30 & This study \\
\hline & Mean & $\Sigma=930$ & 0.21 & 0.006 & 0.19 & 0.23 & 0.04 & 0.19 & \\
\hline \multirow{5}{*}{ Unio tumidus } & & - & - & - & 0.19 & 0.22 & 0.03 & - & 40,41 \\
\hline & & - & 0.20 & - & - & - & - & - & 50 \\
\hline & & - & 0.21 & - & - & - & - & - & 45 \\
\hline & & 720 & 0.21 & 0.007 & 0.18 & 0.25 & 0.07 & 0.33 & This study \\
\hline & Mean & $\sum=720$ & 0.21 & 0.007 & \begin{tabular}{|l|}
0.19 \\
\end{tabular} & 0.24 & 0.05 & 0.24 & \\
\hline
\end{tabular}

Table 1. Descriptive statistics of glochidia for each species measured during this study in comparison to other measurements of the same species. $N$ sample size, SD standard deviation, Min. minimum, Max. maximum, range refers to the maximum difference recorded in all presented data, range/mean size range of the glochidium length variability standardized by the averaged mean sizes presented in the table, $(-)$ not available.

$\mathrm{p}=0.252 ;$ PC2: $\mathrm{b}=0.04, \mathrm{p}=0.880 ;$ PC3: $\mathrm{b}=-0.29, \mathrm{p}=0.302 ; \mathrm{PC} 4: \mathrm{b}=0.32, \mathrm{p}=0.248$ ) and $U$. tumidus (linear regressions; $\mathrm{PC} 1: \mathrm{b}=0.31, \mathrm{p}=0.167 ; \mathrm{PC} 2: \mathrm{b}=-0.41, \mathrm{p}=0.134 ; \mathrm{PC} 3: \mathrm{b}=-0.13, \mathrm{p}=0.642 ; \mathrm{PC} 4: \mathrm{b}=0.39, \mathrm{p}=0.146)$.

\section{Discussion}

Glochidia develop within the environment created by the female mussel and her body size (differing according to habitat and age), which might influence the total amount of energy acquired from the habitat and allocated to progeny ${ }^{51}$. Female size will constrain marsupium size which may set further limits on glochidia numbers but not size or shape. Indeed, in our data, high and significant correlations between female shell length and the wet mass of the gravid marsupium confirm the use of female shell length as a proxy for reproductive output (in accordance with ${ }^{13,47}$ ).

The zero slope of the regression lines of glochidia size against female lengths (i.e. flat reaction norm ${ }^{52}$ ) in all species suggests that the glochidium size might be determined during egg formation (Fig. 1a) and seems to be constrained towards a narrow optimum. It is especially visible in Unio spp.where glochidium size was remarkably consistent across many factors operating at many scales: 

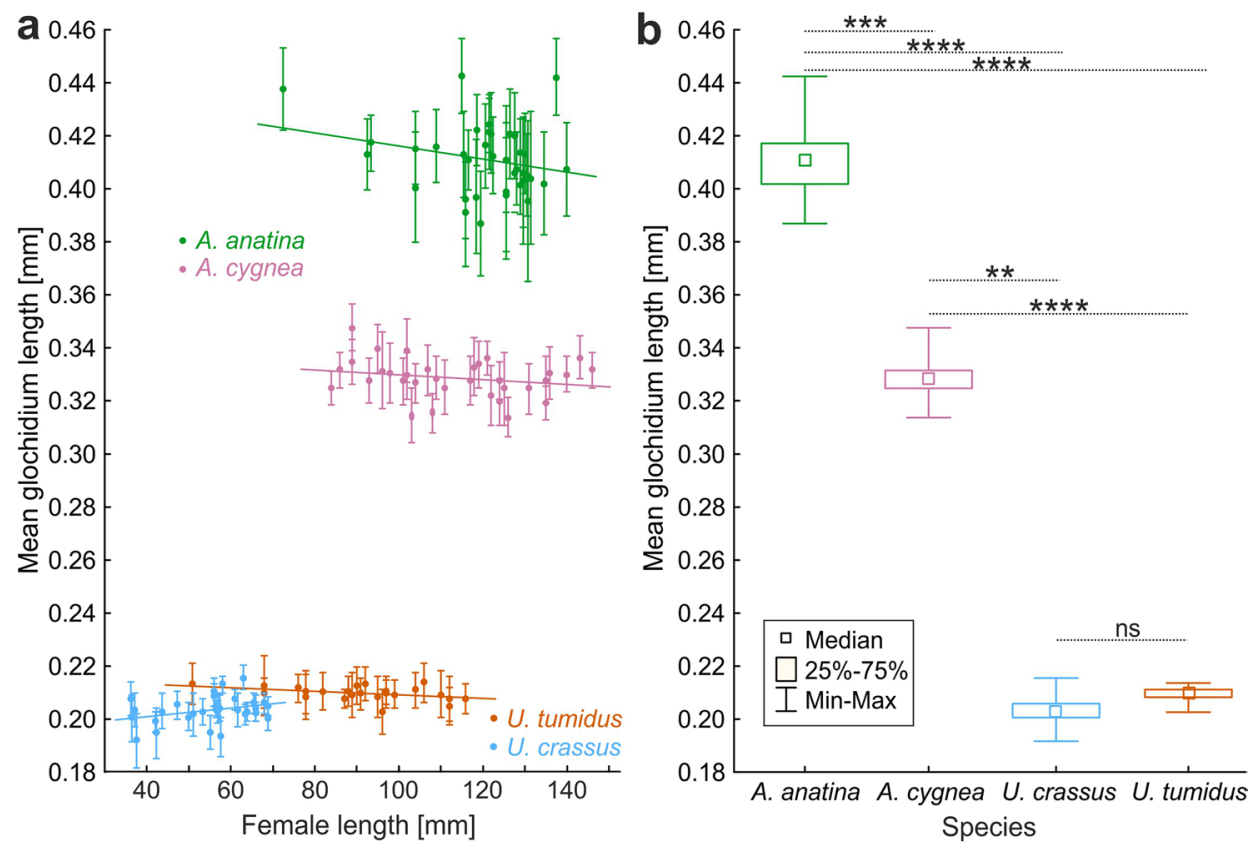

Figure 2. (a) The relationship between female shell length and mean length of its glochidia (mean $\pm S D$ ). (b) Box plots of the differences in mean glochidia size between species with the results of post-hoc tests of differences between species. $n s$ not significant, ${ }^{*} \mathrm{p}<0.05,{ }^{* *} \mathrm{p}<0.01,{ }^{* *} \mathrm{p}<0.001,{ }^{* * * *} \mathrm{p}<0.0001$.

\begin{tabular}{|l|l|l|l|l|r|r|}
\hline Model & Effect & SS & df & \multicolumn{1}{l}{ MS } & \multicolumn{1}{l|}{ F } & \multicolumn{1}{l|}{ p } \\
\hline \multirow{5}{*}{ I (all species) } & Intercept & 7.0 & 1 & 7.0 & 3401.0 & $<0.0001$ \\
\cline { 2 - 7 } & Species & 0.7 & 3 & 0.2 & 117.1 & $<0.0001$ \\
\cline { 2 - 7 } & Female length & 0.002 & 1 & 0.002 & 1.1 & 0.2881 \\
\cline { 2 - 7 } & Species $\times$ female length & 0.01 & 3 & 0.004 & 1.8 & 0.1591 \\
\cline { 2 - 7 } & WSE & 0.005 & 29 & 0.0002 & 1.4 & 0.0610 \\
\cline { 2 - 7 } & WSE $\times$ species & 0.009 & 87 & 0.0001 & 0.8 & 0.9138 \\
\cline { 2 - 7 } & WSE $\times$ female length & 0.004 & 29 & 0.0001 & 1.1 & 0.3851 \\
\cline { 2 - 7 } & WSE $\times$ species $\times$ female length & 0.009 & 87 & 0.0001 & 0.8 & 0.9016 \\
\hline \multirow{5}{*}{ II (Unio crassus only) } & Intercept & 0.08 & 1 & 0.08 & 174.7 & $<0.0001$ \\
\cline { 2 - 7 } & River & 0.0007 & 2 & 0.0003 & 0.7 & 0.4836 \\
\cline { 2 - 7 } & Female length & 0.0008 & 1 & 0.0008 & 1.8 & 0.1922 \\
\cline { 2 - 7 } & River $\times$ female length & 0.001 & 2 & 0.0005 & 1.1 & 0.3565 \\
\cline { 2 - 7 } & WSE & 0.0001 & 29 & 0.000003 & 0.1 & 1.0 \\
\cline { 2 - 7 } & WSE $\times$ river & 0.0004 & 58 & 0.000008 & 0.3 & 1.0 \\
\cline { 2 - 6 } & WSE $\times$ female length & 0.00008 & 29 & 0.000003 & 0.1 & 1.0 \\
\cline { 2 - 6 } & WSE $\times$ river $\times$ female length & 0.0005 & 58 & 0.000009 & 0.3 & 1.0 \\
\hline
\end{tabular}

Table 2. The results of Mixed-design GLMs of the influence of female shell length on glochidia length. WSE within subject effect, $S S$ sum of squares, $d f$ degrees of freedom, $M S$ mean square.

(i) considering phylogeny, glochidia size and variation (Table 2) were stable despite the phylogenetic differences, i.e. both of the Unio species did not differ significantly in glochidial size (0.01 $\mathrm{mm}$ difference) despite the genetic distance between them ${ }^{3}$;

(ii) despite considerable species-specific differences in habitats (e.g. U. crassus numerous in fast-flowing, usually mountainous rivers vs $U$. tumidus occurring rather in lowland rivers and lakes) there was no difference in glochidial size between Unio species;

(iii) within a single species (U. crassus) glochidia size was consistent across different habitats;

(iv) female size did not influence the glochidia size.

The consistent size of glochidia, irrespective of female size, may be explained by the remarkable life history of naiads. Selection to favour the production of many small glochidia confirms the assertion by Ref. ${ }^{23}$ that the 

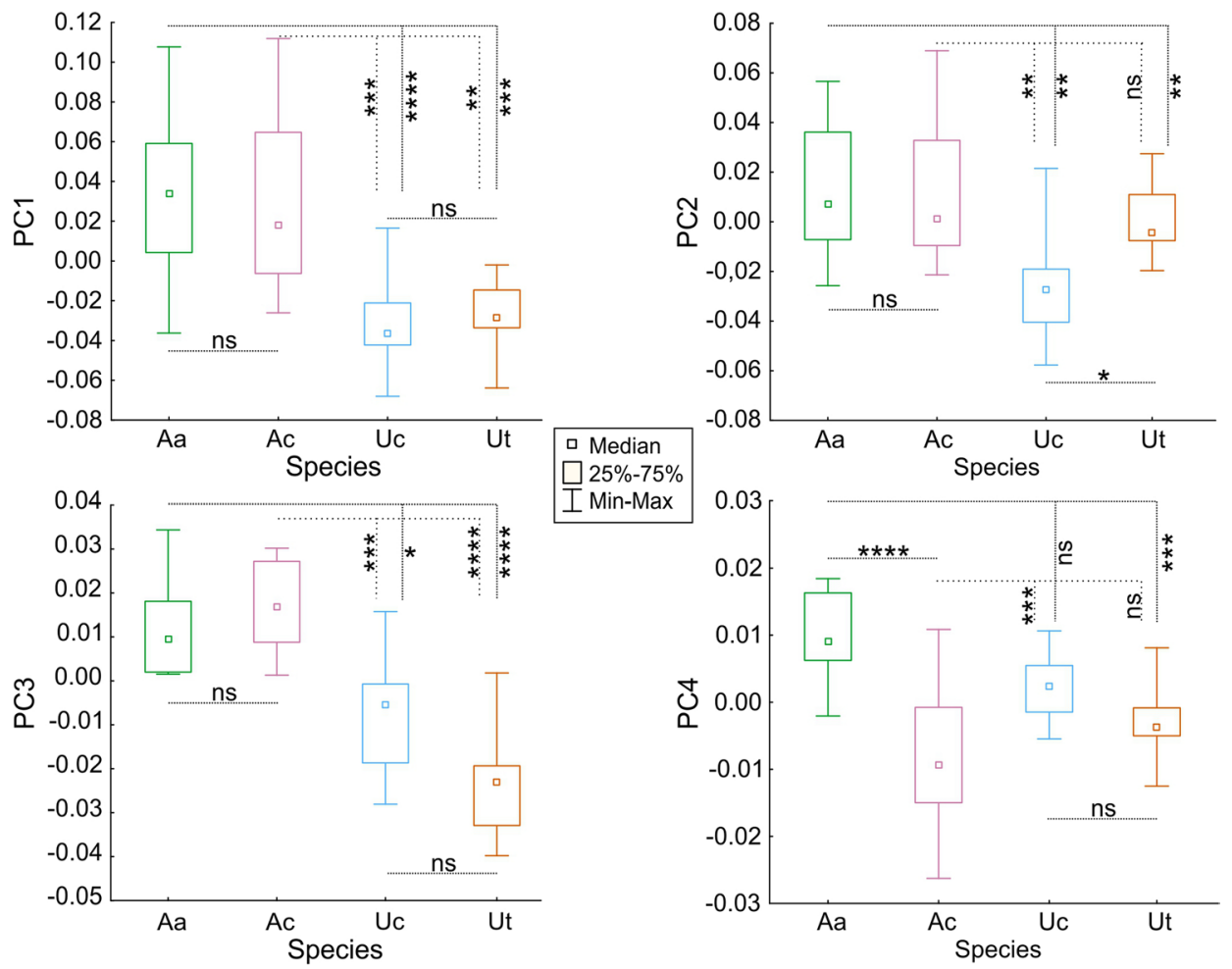

Figure 3. Box plots of the differences in Principal Component scores between species, describing their glochidia shape obtained from Elliptical Fourier Descriptors. Aa, Anodonta anatina; Ac, Anodonta cygnea; Uc, Unio crassus; Ut, Unio tumidus; ns, not significant; ${ }^{*} \mathrm{p}<0.05,{ }^{* *} \mathrm{p}<0.01$, ${ }^{* *} \mathrm{p}<0.001$, ${ }^{* * *} \mathrm{p}<0.0001$.

likelihood of successful encystment, subsequent metamorphosis and continuation to adulthood of an individual glochidium is very small. Selection in favour of a high propagule number is further indicated by the rapid and synchronous release of glochidia seen in many species ${ }^{7,53}$, suggesting that fish encounter rates may be relatively rare. If the density of larvae in the water column influences infestation probability, then glochidia might be small not only because of energy allocation in their number, not size but also their size might be selected against to be able to pack them more tightly ${ }^{54}$ into the restricted space of the shell cavity.

Lack of glochidia size differences within the genus Unio and between different habitats within the same species (U. crassus) nicely evoke J.B.S. Haldane's idea, that there is one 'best' genotype, which is the genotype with the highest fitness ${ }^{55}$. The presence of any additional, less fit genotypes would reduce population mean fitness ${ }^{56}$, leading to its decrease. However, that leads to the prediction that other mussel species must have the same optimal glochidial size, which might be accepted within the genus Unio, but surely is not true for genus Anodonta.

In Anodonta spp.we had no populations of the same species from different habitats. The difference between the two analysed Anodonta species in glochidial size could be attributed to (i) species-specific constraints, or (ii) habitat-related effects; at the moment these two factors cannot be distinguished because we do not have data for both species from multiple sympatric populations. However, drawing from other published studies it is apparent that glochidia of A. anatina are especially variable in size across studies and may attain very large sizes in some locations (Table 1). The atypically large size of A. anatina reported in Ref. $^{28}$ was attributed to hypereutrophic waters, although the population also demonstrated the only record of the species brooding glochidia in all four demibranchs (tetrageny), suggesting other factors may also have contributed to this extreme morphology.

While it is plausible that nutrient-rich waters may result in female mussels investing more energy into each glochidium, variability in glochidia size across populations may also reflect specificity towards particular host fishes. The extreme selective pressure on naiads to successfully attach their glochidia to suitable host fishes has resulted in the evolution of complex lures and attractants in the North American Unionidae ${ }^{29}$. Anodonta spp. are generalists, occupying a wide range of habitats, using a wide range of host fishes and releasing their glochidia into the water column where they may encyst the gills or fins of passing fish ${ }^{3}$. Selection may therefore favour the retention of plasticity in glochidia size to enable optimisation towards site-specific host fishes. For example, small glochidia may disperse passively for longer distances in riverine systems, while large glochidia may be more visible to host fishes that attempt to eat them after which the glochidia attach to the host's gills ${ }^{20}$, or large glochidia may settle more quickly on the benthos where they can encounter benthic-feeding hosts ${ }^{29}$. The different fate of floating glochidia may be attributed also to the shape differences of glochidia: although among Unio species there are no differences in glochidial size, their shape differs in one of the shape aspects. This may lead to the conclusion that the size is strongly selected towards the optimum common for Unio sp., whereas the shape may differ within the size limit. 
The differences in glochidium size between Unio and Anodonta species might be explained based on proximate and ultimate causes. Considering proximate factors, Unio species produce several broods in spring ${ }^{30}$ when low food availability and cool temperatures may limit resources that can be invested in reproduction. Under such conditions, investment in small, fast developing glochidia may prove to be optimal. Anodonta species, on the other hand, produce only one brood per season during late summer and brood it through a much longer period than Unio species ${ }^{57}$, thus facilitating more investment into each glochidium. Considering ultimate explanations, the glochidium is adapted to infesting fish and its size and morphology likely reflect the foraging habits and abundance of the hosts ${ }^{29}$. Anodonta species are relative generalists, using at least 23 species of host fishes ${ }^{3}$ while Unio species are more specialist, with $U$. tumidus known to use only six host fishes and U. crassus 12 species $^{3}$. The broader spectrum of host species used by Anodonta may increase the likelihood of glochidia encountering a suitable host, in which case greater parental investment in each glochidium and its species-specific size and shape may be favoured.

We also show that the differences lie not only in the size of the glochidia but also in their shape. Barnhart et al. ${ }^{29}$ considered the shape of glochidia an important factor concerning host infection strategies. Accepting that in Unio sp. the trade-off between size and number of progeny is biased towards the "number" extreme, one can speculate, that under this assumption the size of glochidium cannot vary, thus cannot evolve, whereas the shape of the glochidium does not influence the trade-off, the same number of glochidia might be produced despite their different shapes (differences in PC2 for Unio sp. and in PC4 for Anodonta sp.).

While size of glochidia may provide some tools for taxonomy. Some research (e.g. Refs. ${ }^{58,59}$ ) suggest that the shape of the glochidium (symmetry, vertical/horizontal elongation) provides useful taxonomic traits, which can be used as a tool in reconstruction of paleoenvironment $s^{35}$. Further understanding of the functional significance of glochidia size and shape may assist with future identification of host fishes and may prove especially useful in the case of rare or poorly studied naiads.

In conclusion, our study demonstrates that glochidium size and shape are under very strong selection towards different optima in different ecological and/or taxonomical groups. The highly conserved glochidia size within $U$. crassus, an endangered and declining species, could be indicative of its narrow host range and suggests that recruitment of the species may be linked closely to the population dynamics of its host fishes. We recommend that closer attention is paid to number, size, shape and variability of glochidia, both within and between mussel species, as this could provide important insights into the ecology and conservation of these important but vulnerable ecosystem engineers.

Received: 29 March 2021; Accepted: 24 November 2021

Published online: 09 December 2021

\section{References}

1. MacArthur, R. \& Wilson, E. O. The Theory of Island Biogeography (Princeton University Press, 1967).

2. Stearns, S. C. The evolution of life history traits: A critique of the theory and a review of the data. Annu. Rev. Ecol. Evol. Syst. 8, 145-171. https://doi.org/10.1146/annurev.es.08.110177.001045 (1977).

3. Lopes-Lima, M. et al. Conservation status of freshwater mussels in Europe: State of the art and future challenges. Biol. Rev. 92, 572-607. https://doi.org/10.1111/brv.12244 (2017).

4. Lopes-Lima, M. et al. Conservation of freshwater bivalves at the global scale: Diversity, threats and research needs. Hydrobiologia 810, 1-14. https://doi.org/10.1007/s10750-017-3486-7 (2018).

5. Ferreira-Rodríguez, N. et al. Research priorities for freshwater mussel conservation assessment. Biol. Conserv. 231, 77-87. https:// doi.org/10.1016/j.biocon.2019.01.002 (2019).

6. Haag, W. R. \& Rypel, A. L. Growth and longevity in freshwater mussels: Evolutionary and conservation implications. Biol. Rev. 86, 225-247. https://doi.org/10.1111/j.1469-185X.2010.00146.x (2011).

7. Haag, W. R. North American Freshwater Mussels: Natural History, Ecology, and Conservation (Cambridge University Press, 2012).

8. Ziuganov, V. et al. Life span variation of the freshwater pearl shell: A model species for testing longevity mechanisms in animals. AMBIO J. Hum. Environ. 29, 102-105. https://doi.org/10.1579/0044-7447-29.2.102 (2000).

9. Wächtler, K., Drehen-Mansur, M. C., \& Richter, T. Larval types and early postlarval biology in Naiads (Unionoida). In Ecology and Evolution of the Freshwater Mussels Unionoida (eds. Bauer, G. \& Wächtler, K.) 93-119 (Springer Science \& Business Media, 2001).

10. Hanson, J. M., Mackay, W. C. \& Prepas, E. E. Effect of size-selective predation by muskrats (Ondatra zebithicus) on a population of unionid clams (Anodonta grandis simpsoniana). J. Anim. Ecol. 58, 15-28. https://doi.org/10.2307/4983 (1989).

11. Bauer, G. The adaptive value of offspring size among freshwater mussels (Bivalvia; Unionoidea). J. Anim. Ecol. 63, 933-944. https:// doi.org/10.2307/5270 (1994).

12. Bauer, G. Framework and driving forces for the evolution of Naiad life histories. In Ecology and Evolution of the Freshwater Mussels Unionoida (eds. Bauer, G. \& Wächtler, K.) 233-257 (Springer Science \& Business Media, 2001).

13. Haag, W. R. The role of fecundity and reproductive effort in defining life-history strategies of North American freshwater mussels. Biol. Rev. 88, 745-766. https://doi.org/10.1111/brv.12028 (2013).

14. Wood, E. M. Development and morphology of the glochidium larva of Anodonta cygnea (Mollusca: Bivalvia). J. Zool. $173,1-13$. https://doi.org/10.1111/j.1469-7998.1974.tb01743.x (1974).

15. Silverman, H., Steffens, W. L. \& Dietz, T. Calcium from extracellular concretions in the gills of freshwater unionid mussels is mobilized during reproduction. J. Exp. Zool. 236, 137-147. https://doi.org/10.1002/jez.1402360204 (1985).

16. Silverman, H., Kays, W. T. \& Dietz, T. H. Maternal calcium contribution to glochidial shells in freshwater mussels (Eulamellibranchia: Unionidae). J. Exp. Zool. 242, 137-146. https://doi.org/10.1002/jez.1402420204 (1987).

17. McIvor, A. L. \& Aldridge, D. C. The reproductive biology of the depressed river mussel Pseudanodonta complanata (Bivalvia: Unionidae) with implications for its conservation. J. Molluscan Stud. 73, 259-266. https://doi.org/10.1093/mollus/eym023 (2007).

18. Neves, R. J., Bogan, A. E., WIlliams, J. D., Ahlstedt, S. A., \& Hartfield, P. W. Status of aquatic mollusks in the southeastern United States: A downward spiral of diversity. In Aquatic Fauna in Peril: A Southeastern Perspective (eds. Benz, W. \& Collins, D. E.) 43-85 (Southeast Aquatic Research Institute, 1997).

19. Kat, P. W. Parasitism and the Unionacea (Bivalvia). Biol. Rev. 59, 189-207. https://doi.org/10.1111/j.1469-185X.1984.tb00407.x (1984).

20. Ćmiel, A. M., Zając, K., Lipińska, A. M. \& Zając, T. Glochidial infestation of fish by the endangered thick-shelled river mussel Unio crassus. Aquat. Conserv. Mar. Freshw. Ecosyst. 28, 535-544. https://doi.org/10.1002/aqc.2883 (2018). 
21. Modesto, V. et al. Fish and mussels: Importance of fish for freshwater mussel conservation. Fish Fish. 19, 244-259. https://doi.org/ $10.1111 /$ faf.12252 (2018).

22. Jansen, W. A. \& Hanson, M. J. Estimates of the number of glochidia produced by clams (Anodonta grandis simpsoniana Lea) attaching to yellow perch (Perca flavescens) and surviving to various ages in Narrow Lake, Alberta. Can. J. Zool. 69, 973-977. https://doi. org/10.1139/z91-141 (1991).

23. Young, M. \& Williams, J. The reproductive biology of the freshwater pearl mussel Margaritifera margaritifera (Linn.) in Scotland. II Laboratory studies. Arch. Hydrobiol. 100, 29-43 (1984).

24. Zimmerman, L. \& Neves, R. J. Effects of temperature on duration of viability for glochidia of freshwater mussels (Bivalvia: Unionidae). Am. Malacol. Bull. 17, 31-35 (2002).

25. Haag, W. R. \& Warren, M. L. Host fishes and infection strategies of freshwater mussels in large Mobile Basin streams, USA. J. N. Am. Benthol. Soc. 22, 78. https://doi.org/10.2307/1467979 (2003).

26. Ćmiel, A. M., Zając, T., Zając, K., Lipińska, A. \& Najberek, K. Single or multiple spawning? Comparison of breeding strategies of freshwater Unionidae mussels under stochastic environmental conditions. Hydrobiologia 848, 3067-3075. https://doi.org/10. 1007/s10750-019-04045-8 (2021)

27. Lillie, F. R. The embryology of the unionidae. A study in cell-lineage. J. Morphol. 10, 1-100. https://doi.org/10.1002/jmor.10501 00102 (1895).

28. Lopes-Lima, M. et al. The strange case of the tetragenous Anodonta anatina. J. Exp. Zool. 325, 52-56. https://doi.org/10.1002/jez. 1995 (2016).

29. Barnhart, M. C., Haag, W. R. \& Roston, W. N. Adaptations to host infection and larval parasitism in Unionoida. J. N. Am. Benthol. Soc. 27, 370-394. https://doi.org/10.1899/07-093.1 (2008).

30. Zając, K. \& Zając, T. A. Seasonal patterns in the developmental rate of glochidia in the endangered thick-shelled river mussel. Unio crassus Philipsson. 1788. Hydrobiologia 848, 3077-3091. https://doi.org/10.1007/s10750-020-04240-y (2021).

31. Jones, J. W., Mair, R. A. \& Neves, R. J. Factors affecting survival and growth of juvenile freshwater mussels (Bivalvia: Unionidae) cultured in recirculating aquaculture systems. N. Am. J. Aquac. 67, 210-220. https://doi.org/10.1577/A04-055.1 (2005).

32. Iwata, H. \& Ukai, Y. SHAPE: A computer program package for quantitative evaluation of biological shapes based on elliptic Fourier descriptors. J. Hered. 93, 384-385. https://doi.org/10.1093/jhered/93.5.384 (2002).

33. Freeman, H. Computer processing of line drawing images. ACM Comput. Surv. 6, 57-97. https://doi.org/10.1145/356625.356627 (1974).

34. Kuhl, F. P. \& Giardina, C. R. Elliptic Fourier features of a closed contour. Comput. Gr. Image Process. 18, 236-258. https://doi.org/ 10.1016/0146-664X(82)90034-X (1982).

35. Aldridge, D. C. \& Horne, D. C. Fossil glochidia (Bivalvia. Unionidae): Identification and value in palaeoenvironmental reconstructions. J. Micropalaeontol. 17, 179-182. https://doi.org/10.1144/jm.17.2.179 (1998).

36. Antonova, L. A. \& Starobogatov, Y. I. Generic differences of glochidia of naiades (Bivalvia Unionoidea) of the fauna of USSR and problems of the evolution of glochidia. Systematics and Fauna of Gastropoda. Bivalvia and Cephalopoda. Proc. Zool. Inst. Leningr. 187, 129-154 (1988) (in Russian).

37. Niemeyer, B. Vergleichende Untersuchungen zur bionomischen Strategie der Teichmuschelarten Anodonta cygnea L. und Anodonta anatina L. PhD thesis, Institut für Zoologie der Tierärztlichen Hochschule (1992) (in German).

38. Harms, W. Postembryonale Entwicklungsgeschichte der Unioniden. Zool. Jb. 28, 325-386 (1909) (in German).

39. Hüby, B. Zur Entwicklungsbiologie der Fließgewässermuschel Pseudanodonta complanata. PhD thesis, Institut für Zoologie der Tierärztlichen Hochschule (1988) (in German).

40. Nagel, K. O. Anatomische, morphologische und biochemische Untersuchungen zur Taxonomie und systematik der europäischer Unionacea (Mollusca: Bivalvia). PhD Dissertation, Universitat des Landes Hessen (1988) (in German).

41. Nagel, K. O. Anatomische und morphologische Merkmale europäischer Najaden (Unionoidea: Margaritiferidae und Unionidae) und ihre Bedeutung für die Systematik. Heldia 2, 3-48 (1999) (in German).

42. Pekkarinen, M. \& Englund, V. P. M. Sizes of intramarsupial unionacean glochidia in Finland. Arch. Hydrobiol. 134, 379-391. https:// doi.org/10.1127/archiv-hydrobiol/134/1995/379 (1995).

43. Escobar-Calderón, J. F. \& Douda, K. Variable performance of metamorphosis success indicators in an in vitro culture of freshwater mussel glochidia. Aquaculture 513, 734404. https://doi.org/10.1016/j.aquaculture.2019.734404 (2019).

44. Huber, V. M. M. Host Fish Suitability for the Endangered Native Anodonta and Impacts of the Invasive Sinanodonta Woodiana on Their Reproductive Success. PhD Thesis, Technische Universität München (2019).

45. Scharsack, G. Licht-und Elektronenmikroskopische Untersuchungen an Larvalstadien einheimischer Unionacea (Bivalvia; Eulamellibranchiata). PhD Thesis, University of Hannover (1994) (in German).

46. Hoggarth, M. A. Descriptions of some of the glochidia of the Unionidae (Mollusca: Bivalvia). Malacologia 41, 1-118 (1999).

47. Başçınar, N. S. \& Düzgüneş, E. A preliminary study on reproduction and larval development of Swan Mussel [Anodonta cygnea (Linnaeus, 1758)] (Bivalvia: Unionidae) in Lake Çıldır (Kars, Turkey). Turk. J. Fish. Aquat. Sci. 9, 23-27 (2009).

48. Sayenko, E. M. The microsculpture of glochidia of some Anodontine bivalves (Unionidae). Biol. Bull. 43, 127-135. https://doi.org/ $10.1134 / \mathrm{S} 1062359016020072(2016)$.

49. Claes, M. Untersuchungen zur Entwicklungsbiologie der Teichmuschel Anodonta cygnea. PhD Thesis, Institut für Zoologie, Tierärztliche Hochschule Hannover (1987) (in German).

50. Maaß, S. Untersuchungen zur Fortpflanzungsbiologie einheimischer Süßwassermuscheln der Gattung Unio. PhD Dissertation, Institut für Zoologie, Tierärztliche Hochschule Hannover (1987) (in German).

51. Heino, M. \& Kaitala, V. Evolution of resource allocation between growth and reproduction in animals with indeterminate growth. J. Evol. Biol. 12, 423-429. https://doi.org/10.1046/j.1420-9101.1999.00044.x (1999).

52. Flatt, T. The evolutionary genetics of canalization. Q. Rev. Biol. 80, 287-316. https://doi.org/10.1086/432265 (2005).

53. Hastie, L. C. \& Young, M. R. Timing of spawning and glochidial release in Scottish freshwater pearl mussel (Margaritifera margaritifera) populations. Freshw. Biol. 48, 2107-2117. https://doi.org/10.1046/j.1365-2427.2003.01153.x (2003).

54. Glazier, D. S. Smaller amphipod mothers show stronger trade-offs between offspring size and number. Ecol. Lett. 3, 142-149. https://doi.org/10.1046/j.1461-0248.2000.00132.x (2001).

55. Reznick, D. Hard and soft selection revisited: How evolution by natural selection works in the real world. J. Hered. 107, 3-14. https://doi.org/10.1093/jhered/esv076 (2016).

56. Haldane, J. B. S. The effect of variation on fitness. Am. Nat. 71, 337-349 (1937).

57. Aldridge, D. C. The morphology, growth and reproduction of Unionidae (Bivalvia) in a fenland waterway. J. Molluscan Stud. 65, 47-60. https://doi.org/10.1093/mollus/65.1.47 (1999).

58. Chernyshev, A. V., Sayenko, E. M. \& Bogatov, V. V. Superspecific taxonomy of the far eastern unionids (Bivalvia. Unionidae): Review and analysis. Biol. Bull. 47, 267-275. https://doi.org/10.1134/S1062359020010045 (2020).

59. Pfeiffer, J. M. III. \& Graf, D. L. Evolution of bilaterally asymmetrical larvae in freshwater mussels (Bivalvia: Unionoida: Unionidae). Zool. J. Linnean Soc. 175, 307-318. https://doi.org/10.1111/zoj.12282 (2015). 


\section{Acknowledgements}

This study was financed by the statutory funds of the Institute of Nature Conservation Polish Academy of Science. This publication is based upon work from COST Action CA18239, supported by COST (European Cooperation in Science and Technology).

\section{Author contributions}

T.Z., A.M.Ć., K.Z., D.C.A. and M.L.-L. designed the study. A.M.Ć., J.D., T.Z, K.Z., D.C.A., A.L and M.L.-L. collected data. T.Z., A.M.Ć., J.D., K.Z, and D.C.A. wrote the main manuscript text. J.D., F.T. and A.L. measured glochidia. A.M.Ć. conducted statistical analysis, Eliptical Fourier descryptors analysis, and prepared Table 2. K.Z. and T.Z. prepared Table 1 and Figs. 1, 2, 3. All authors reviewed the manuscript.

\section{Competing interests}

The authors declare no competing interests.

\section{Additional information}

Correspondence and requests for materials should be addressed to J.D.

Reprints and permissions information is available at www.nature.com/reprints.

Publisher's note Springer Nature remains neutral with regard to jurisdictional claims in published maps and institutional affiliations.

(c) (i) Open Access This article is licensed under a Creative Commons Attribution 4.0 International cc) License, which permits use, sharing, adaptation, distribution and reproduction in any medium or format, as long as you give appropriate credit to the original author(s) and the source, provide a link to the Creative Commons licence, and indicate if changes were made. The images or other third party material in this article are included in the article's Creative Commons licence, unless indicated otherwise in a credit line to the material. If material is not included in the article's Creative Commons licence and your intended use is not permitted by statutory regulation or exceeds the permitted use, you will need to obtain permission directly from the copyright holder. To view a copy of this licence, visit http://creativecommons.org/licenses/by/4.0/.

(C) The Author(s) 2021 